\title{
Solar energy for self-contained power supply
}

\author{
Maxim Zholobov ${ }^{1}$, Margarita Gubaeva ${ }^{1}$, Nikolai Kachalov ${ }^{1,}{ }^{*}$, and Olga Kachalova $^{2}$ \\ ${ }^{1}$ National Research Tomsk Polytechnic University, 634050 Tomsk, Russia \\ ${ }^{2}$ The Russian Presidential Academy of National Economy and Public Administration, 634050, Tomsk \\ Russia
}

\begin{abstract}
Solar energy relevance in self-contained utility system as well as economic feasibility for each class of consumers considered. The article will outline utilising features of self-contained photovoltaic stations in Middle East and Northern Africa.
\end{abstract}

\section{Introduction}

The world is increasingly interested in solar energy for technologies development and cutting of production costs together with conventional energy sources dearness, which have remained so for the last few years.

Middle East and Northern Africa (MENA) bear enormous potential for solar power development. After numerous theoretical studies and successful experiments conducted, the idea to harness and transform solar energy is gradually being implemented in these countries.

The challenge of responding remote regions utility-scale, industrial-scale and agricultural demand for electrical and thermal power, as well as the issues of sustainable growth and lowering polluting effect of energy production necessitates renewable energy development. By now there are national plans of renewable energy development in the number of countries. Mostly they focus on wind, solar and biomass energy.

Wide practical application of the first two is limited by well-understood disadvantages like low energy flux density and intermittence which result in significant costs on energy collection, storage and converting facilities. With regard to geographical position and climate pattern of MENA, using solar energy for power generation appears to be the most prospective method.

Relevance of solar energy as the power generation source is investigated in terms of MENA. Geographical location of these countries caused a big amount of isolated settlements long-distanced from well-developed grid. According to economic factors such as underpopulation and because of low energy demand these countries cannot be powered on to the grid. Self-contained utility system based on alternative energy can solve this problem.

\footnotetext{
* Corresponding author: mtfl@mail.ru
} 


\section{Solar irradiation characteristics}

Solar power is an alternative energy, based on conversion of sunlight energy into any form. It is a renewable energy and is 'environmentally friendly', i.e. it is non-polluting during the active phase of utilising.

Solar energy comes from nuclear fusion [1] of hydrogen in the Sun core which is under high-pressure. Solar emission attenuated while direct solar radiation permeates the atmosphere and reaches the surface of Earth as direct and diffused light which behave differently: direct irradiation is manageable by various optical systems, while diffused light defy accumulation and control.

A unitary standard of solar energy measurements due to European Commission and International Electrotechnical Commission recommendations accepted normal atmosphere pressure [2]. Subsequently an additional decision was taken [3].

\section{Solar power potential}

Solar energy application efficiency mostly depends on the accuracy of designs in patterns and exact data on solar radiation arrival at the intended operation facilities. Creating minimum cost competitive solar units efficiently meeting the demand linked with the rationale for solar receivers optimum area, batteries rated power, type and capacity. Due to relatively low solar radiation flux density near Earth surface, the area of the prime mover receivers can be large so the receivers contribute to the whole facility cost.

Daily, seasonal, and weather intermittence of primary energy necessitates appliance of batteries and their capacity determines facility operating receivers size as well as the capacity of energy backup and, consequently, technical-and-economic indexes of the facility as a whole [4].

In general case information on solar irradiation flow and total incident energy can be obtained in the following ways:

- analytical, when the necessary parameters for a specific geographic point are determined by calculations;

- direct (usually short-term) measurements on site;

- unified methodology multi-year measurements at weather stations, the results of which are accumulated in climatic reference guides and databases.

The main source of the initial actinometric information is climatic reference guides and databases created by specialized organizations on the basis of long-term meteorological observations at weather stations results processing $[5,6]$.

We will consider solar power efficiency in terms of MENA.

MENA power development is influenced mainly by factors of own energy sources supply. But oil usage expansion magnifies environmental problems, moreover, recent political events proved that oil-fields cannot guarantee reliable energy supply and the orientation only on them put country's security at risk.

Solar power growth involves difficulties like the fact that the most suitable areas for its development are located far from water sources, and the most populated water adjacent areas do not have such favorable conditions for solar energy production.

Solar energy application contains two main issues: converting it into electricity and heat. By type of application solar power is divided into grid and self-contained utilities. The former includes solar power plants as a part of the grid or centralized system of the existing modern electric power industry, including transportation and distribution. In this case, at solar power plants even with a small relative density (capacity) among the traditional generating capacitance, no significant batteries are required for power fluctuations are damped by the grid $[7,8]$. 
Self-contained solar power plants provide individual consumers, both connected and not connected with the grid. In the first case significant storage is not required as well for the grid supplies if solar energy deficiency happens, and intakes the energy surplus $[9,10]$.

According to the existing principle of solar energy conversion, solar power plants are divided into photovoltaic, implementing the method of direct (no-machine) conversion of solar energy into electrical energy, and thermodynamic in which radiant energy firstly converted into thermal, then in thermodynamic cycle of thermal machine the heat is converted into mechanical energy, and then in generating unit it's converted into electrical energy.

For these purposes various circuitry implemented. Management system tasks are:

- maximum efficiency of renewable energy utilising;

- generated and consumed electricity balancing, in most cases requiring batteries in the energy system;

- power converters operation control, generated electricity parameters regulation [11].

Photovoltaic method is preferable for self-contained low power solar plants (hundreds of Ws to tens of $\mathrm{kWs}$ ) because of its constructive simplicity, which makes it more convenient to operate.

For the mentioned reasons, the fastest growth is observed in the field of photovoltaic plants. Beyond that, close attention is paid to the development of self-contained photovoltaic power plants for certain categories of consumers, for whom powering on to the grid is economically inefficient. This applies primarily to such consumers as pipelines cathodic protection stations, mobile networks current supply stations and remote agricultural consumers [12].

\section{Self-contained photovoltaic stations}

Photovoltaic power plants are self-contained supply systems based on renewable solar energy. This product is a source of energy to meet the needs of consumers not having a permanent connection to electric grids in the area. A significant benefit of these stations is the possibility to expand capacities with minimum costs for mechanical and start-up works, as well as to decrease power output while practical energy saving using modular solutions [13].

Mobile networks current supply photovoltaic stations. The issue of alternative energy supplying cellular network objects is being actively addressed. The focus is on the developing countries of MENA, where local energy networks often unreliable, and alternative energy sources available.

Microwave network in MENA consists of retransmission stations. The total number of photovoltaic stations in communication is currently well over 180 units with total capacity by the end of 2015 .

Photovoltaic power plants in cathode protection. There is a wide network of pipelines in MENA. According to climatic conditions hybrid power plants are usually located at each cathode protection station. Implementation efficiency directly connected to the features of the region where consumers live. Presence of more than one energy source and overhead transmission lines absence along the pipeline routes significantly increase the certainty of power supply $[14,15]$.

Sometimes, to provide synchronous efficient operation of several cathode protection stations as well as other low-power consumers gas engine generator or gas turbine/ by-pass accumulator combination is used. Battery usage allows equating the graphics of power output and load, due to it all units repair interval increases and fuel consumption reduces.

For most countries the main obstacle to electrification of residential areas or regions remote from electrical grid is financial. High-voltage lines extension through the desert for 
electricity transmission to several hundred inhabitants is too cost-consuming. In many underpopulated countries electricity is available only in cities, and there is no onsite grid for feeding the rural areas.

\section{Conclusion}

1. Solar batteries application as well as self-contained solar power plants potential is undoubtable. Modern trends in this field show that solar energy large-scale implementation is unrelated to the problem development layer, but primarily to the economic feasibility for each class of consumers.

2. Based on climatic conditions, population density and remoteness of consumers from the grid, in MENA the front most is self-contained photovoltaic plants.

\section{References}

1. P. Mints, Refocus., 7, 34 (2006), DOI: 10.1016/S1471-0846(06)70657-6

2. H. M. Brandhorst, Terrestrial solar cell calibration and measurement procedures. Proceedings of the Inter. Photovoltaic Solar Energy Conf., Luxemburg, 26-29 May 1977 (Reidel Publ. Co., Dordrecht-Boston, 1978)

3. Terrestrial Photovoltaic Measurement Procedures (Technical Memorandum 73702, NASA, Cleveland, Ohio, 1977)

4. R. E. H. Sims, Solar Energy, 76, 9 (2004), DOI: 10.1016/S0038-092X(03)00101-4

5. A. S. Alam, L. S. Dooley, A. S. Poulton, Energy efficient relay-assisted cellular network model using base station switching, IEEE Global Telecommunications (GLOBECOM 2012): 2nd International Workshop on Multicell Cooperation, 3-7 December 2012 (Anaheim (California), USA, 2012)

6. A. F. Bosch, Dynamic base station energy saving with relays: Research/Master Thesis (UPC - $\quad$ Tsinghua University, 2011) URL: http://upcommons.upc.edu/pfc/bitstream/2099.1/10991/1/PFC.pdf

7. T. Lambert, P. Gilman, P. Lilienthal, Micropower system modeling with homer (John Wiley and Sons, 2005), DOI: 10.1002/0471755621.ch15

8. A. Balastov, N. Kachalov, E. Senkiv, O. Kachalova, MATEC Web of Conferences, 110, 01008 (2017), DOI: 10.1051/matecconf/201711001008

9. J. Lorincz, T. Garma, G. Petrovic, Sensors, 12, 4281 (2012), DOI: $10.3390 / \mathrm{s} 120404281$

10. D. Lee, S. Zhou, Z. Niu, GLOBECOM - IEEE Global Telecommunications Conference, 6134083 (2011), DOI: 10.1109/GLOCOM.2011.6134083

11. S. V. Glushkov, N. A. Kachalov, E. Senkiv, V. Glushkova, Matec Web of Conferences, 92, 01072 (2016), DOI: 10.1051/matecconf/20179201072

12. C. Lubritto, Telecommunication Power System: Energy Saving, Renewable Sources and Environmental Monitoring in Trends in Telecommunications Technologies, ed. by C.J. Bouras (InTech, 2010), DOI: 10.5772 / 8493

13. O. Arnold, F. Richter, G. Fettweis, O. Blume, Future Network and Mobile Summit, $5722444(2010)$

14. S. N. Roy, International Telecommunications Energy Conference (Proceedings), 4664025 (2008), DOI: 10.1109/INTLEC.2008.4664025

15. J. Eyer, G. Corey, Energy Storage for the Electricity Grid: Benefits and Market Potential Assessment Guide (Nova Science Publishers, Inc., USA, 2011) 